\title{
A New Branch of Medicine
}

\author{
Andrew Hague* \\ *President, professor of Advanced Medicine, CellSonic: Manufacturers of Medical Equipment, United Kingdom
}

Received: September 14, 2017; Accepted: September 22, 2017; Published: October 16, 2017

*Corresponding author: Andrew Hague, President, Professor of Advanced Medicine, CellSonic: Manufacturers of Medical Equipment, United Kingdom, Tel: +1315210 6307; E-mail: CellSonic.beauty@gmail.com

\section{Opinion}

In the beginning there were two branches of medicine and only two were needed. We crawled from our caves early to forage all day for food. Fire was useful even though it burned down some dens before we were ready to leave for a cleaner, less ravaged new site. We discovered what plants were good to eat and which were poisonous. Some were used to heal and they became today's pharmaceutical industry. We found ways to cut plants, animals and enemies and this became surgery.

It was a strenuous life. There was no thought of exercise. Mere existence was physically exhausting which was fine because we had evolved to be on the go all day. Back in the cave we were with people we had grown up with. There were no secrets. We supported each other. Those who were lucky enough to not be caught by a tiger or the tribe over the hill lived to an old age, maybe sixty winters and they died in their sleep. [Figure1]

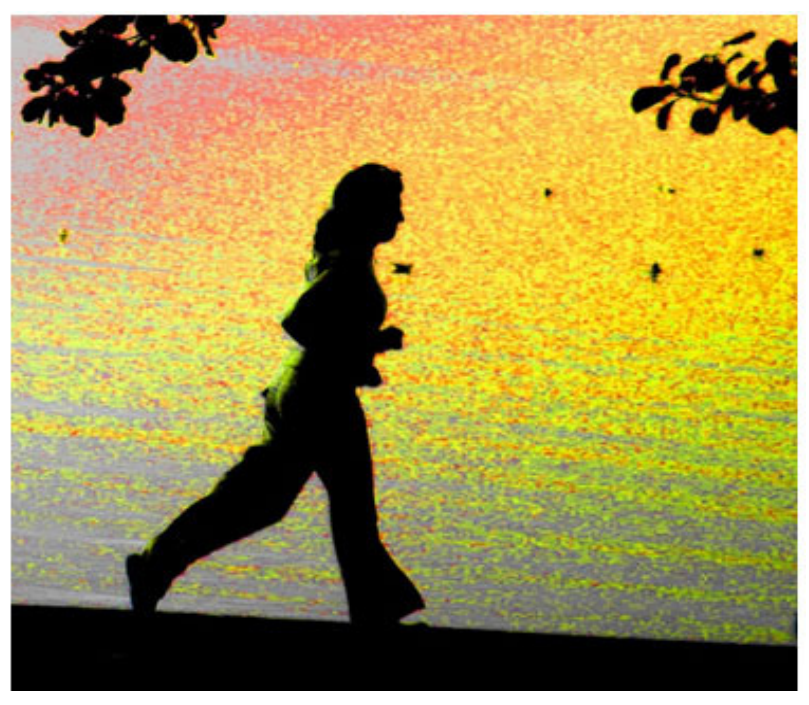

Figure 1
Modern life is vastly different. All the pharmaceuticals have side effects. Surgery is invasive with side effects. If one problem is solved, more are created by cutting the body. The main difference is that life today does not suite the mind and body of the human who evolved only 60,000 years ago. Even for those who are physically active, there is mental stress, pollution that goes beyond the body's ability to eliminate the poison and a life style which corrupts the process of replicating body cells. Ancient creatures such as sharks and ants who existed for millions of years do not replicate their body cells so they do not get cancer. Homo sapiens are still an unstable species and it is the vulnerability of the cell replication process that leads to cancer. [Figure 2]

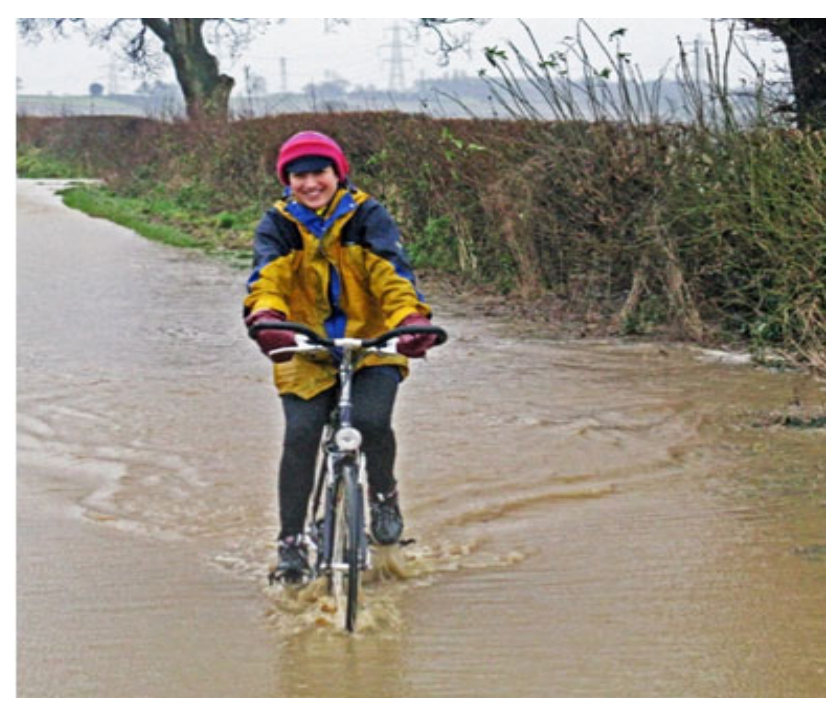

Figure 2

Fortunately, this innovative creature who created a dangerously lazy life has also invented a new branch of medicine that is non-invasive, does not use drugs, has no side effects and cures cancer. The invention is the CellSonic VIPP machine. Some would say that this is the machine that will save humanity. That accolade should go to the bicycle. If everyone cycled, CellSonic would not be needed and lifestyles would have all the benefits 
enjoyed by cavemen without predators. But not everyone will cycle so CellSonic VIPP technology is essential.

What CellSonic does is readily apparent. How is does it will take years of research to explain. CellSonic Limited, the manufacturer of the CellSonic VIPP (Very Intense Pressure Pulse) machines, is collaborating with researchers at universities in England, Germany and India to teach the academics and in turn acquire further knowledge. In England the permittivity of the body cells can be measured to detect tumours less than $1 \mathrm{~mm}$ across before a patient knows they have a problem. CellSonic switches the tumour from malign to benign and will either eradicate the tumour or leave it to the immune system to get rid of it. The protocol requires that no chemotherapy be in the body and if any has been administered at least a month must elapse before using CellSonic.

Chemotherapy destroys the immune system. Supporting the immune system is an essential part of the cure. Early Stone Age humans with organic food, friendship and exercise had good immune systems.

The medical fraternity in the civilised west, mostly Europe and America, treats the body as controllable with bio-chemistry meaning drugs. China appreciates the role of nerves and uses acupuncture to adjust the links between mind and body. Indian meditation sees an important role for the purity of the mind to correct the body's illnesses. Only in the West do pharmaceuticals dominate.

The civilized west is rigged against medical innovation. Despite persistent pleads for breakthroughs, scepticism is uppermost in doctors' minds and health regulators refuse new ideas unless they are accompanied by millions of dollars to pay their own researchers to re-invent the wheel. Even then, many years can pass between breakthrough and implementation during which time pain and suffering increases.

The CellSonic method for wound healing was announced in the year 2000. The British National Institute for Clinical Excellence that advises the National Health Service, the government owned supplier of doctors and hospitals, still classes CellSonic as experimental and does not accept that they have a wound problem in Britain despite their amputation rate having risen to 140 a week from 100 only two years ago. If CellSonic was used to heal wounds, the NHS in Britain would save about $£ 5$ billion a year and release 2.2 million people and their families from misery. These numbers can be scaled up pro-rata across the world. The remedy is available now. Money and lives are being wasted because the managers of health systems refuse to accept the evidence of published, peer reviewed clinical papers. Ignorance kills.

The VIPP technique is neither pharmaceutical nor invasive surgery so it is a new branch of medicine. It heals and cures much that other methods cannot solve. Non-healing wounds such as diabetic ulcers are best healed by CellSonic VIPP. Aches and pains are not masked; their cause is corrected by the pressure pulses to make a permanent cure. Nerves are repaired. Cancer is the failure of cell replication. When mutated cells appear, attempts are made to kill them by radiation or chemotherapy which certainly kills, it kills the patient. [Figure 3]

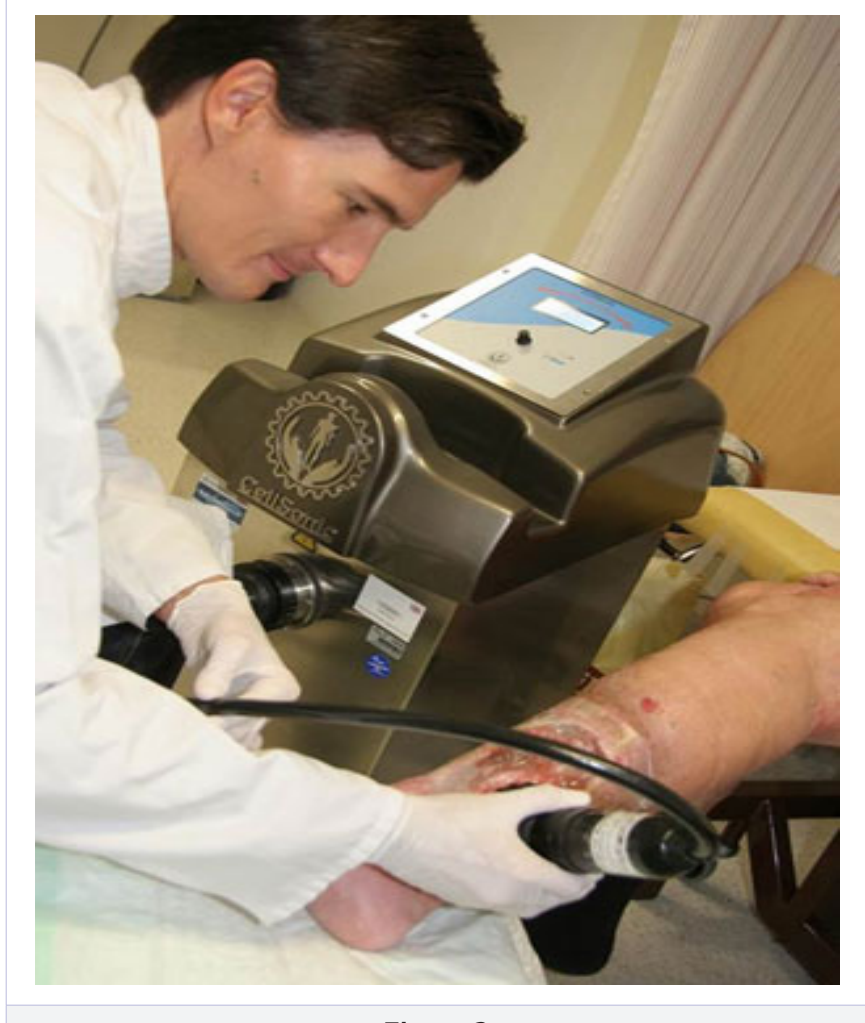

Figure 3

Wound healing has been studied by Dr Christian Busch at Tübingen University in Germany and he concludes that the best of all methods is CellSonic VIPP. It also costs less and leads to permanent closure of the wound thereby removing the cost burden of unending dressings. After the studies, Professor Busch left the university, took his CellSonic machine with him and opened his own clinic in Switzerland where he trebled his income healing wounds for people who will pay out of their own pocket. He has recently tackled a few cases of cancer. CellSonic cannot push its customers; they progress as their confidence builds and Christian is a doctor who thinks for himself. [Figure 4]

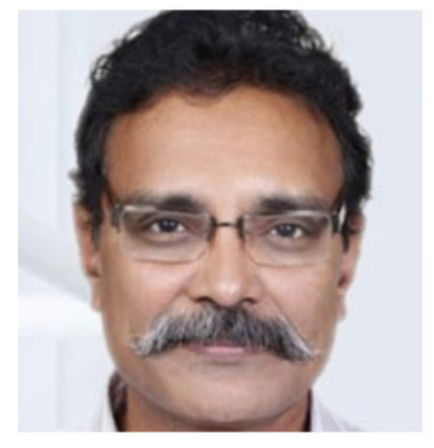

Figure 4 
Nerve repair is evident in wound healing. The new skin is sensitive and almost without scars. Nerves have grown in the new skin. In Hyderabad in India Professor Ramesh Chouhan, using his CellSonic VIPP machine has treated an 18 years old girl whose spinal cord was severed in a traffic crash four years ago and left paralysed from the waist downwards. After three treatments each four days apart the girl is now able to walk and her improved confidence is giving her increased mobility. The treatments will continue. There are no side effects. The pulses were applied to her spine and right down both legs. She had no pain. It is only when she senses the pulses that it is known that the nerves are being restored. [Figure 5]

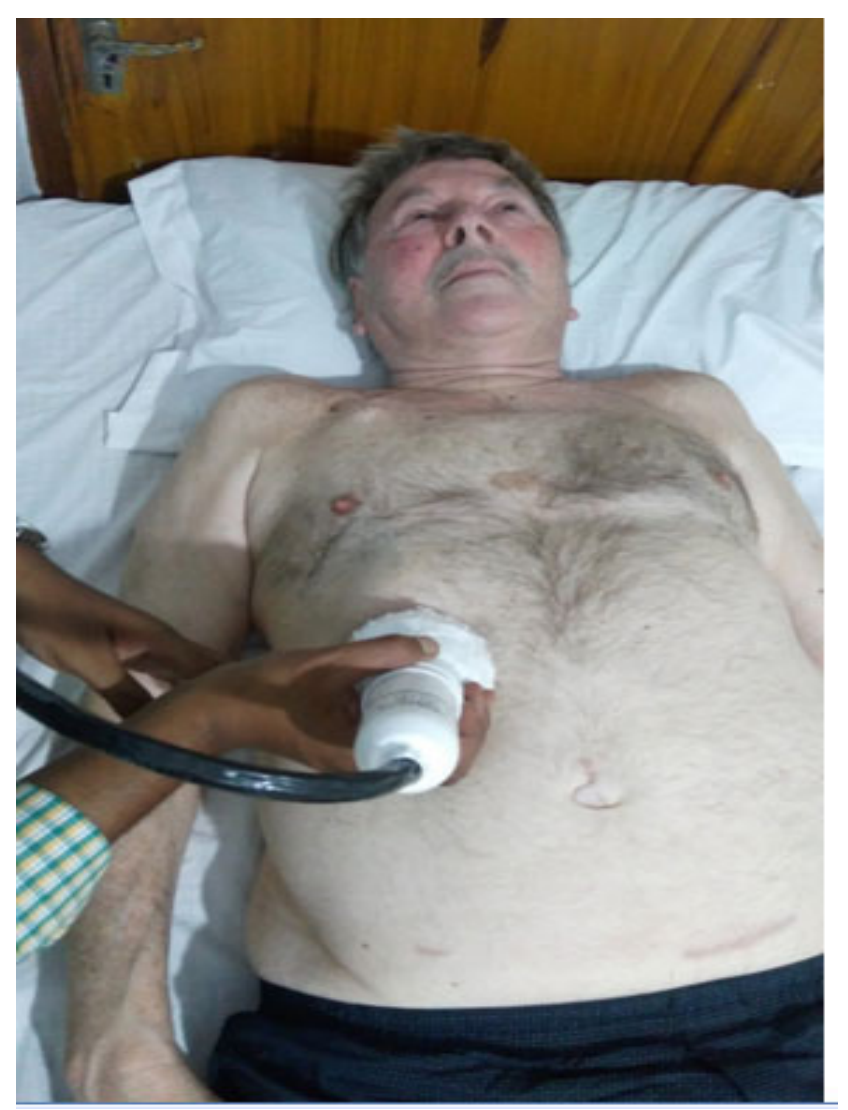

Figure 5
The same professor has cured cancer. He has followed the guidance of Professor Andrew Hague, the president and founder of CellSonic who invented the cure for cancer in 2016. It was applied first to patients in India and a few weeks later in Peru. The logic was that for forty years, similar technology had bombarded stones in the kidneys without side effects and there were no reports of causing cancer. That safety factor was essential. It was hypothesised that pressure kills cancer. It is known that cold and heat kills cancer but there had been previously been no means of applying pressure. In some cases, cancer is believed to be caused by infections and it is known from wound healing that all infections are killed by very intense pressure pulses. Confident that the procedure is safe, the first cancer patients were treated with immediate success. Any pain ceased straight away and within two days the patients reported that they felt better and in some cases they were saying they were cured. Tests and scans took longer so it was two weeks before confirmation came in that the cancer was gone. To date about a hundred patients have been cured of cancer with a success rate of $100 \%$.

A local business man in Hyderabad suffered from arthritis. Prof Chouhan cured the arthritis with CellSonic and that man has insisted on opening a CellSonic Clinic in the city centre. A television company has made films and the publicity is spreading.

CellSonic Limited will be pleased to give more detailed explanations of the technology and protocols to serious enquiries so that as soon as possible the whole world can benefit. The company is already represented in many countries. In all cases, CellSonic has the lowest cost of cure and often the only cure. 